Available online at GSC Online Press Directory

GSC Biological and Pharmaceutical Sciences

e-ISSN: 2581-3250, CODEN (USA): GBPSC2

Journal homepage: https://www.gsconlinepress.com/journals/gscbps

(RESEARCH ARTICLE)

\title{
A comparative study on Naproxen Sodium tablets formulating with different super disintegrants
}

\author{
Sikdar K M Yasif Kayes ${ }^{1,}{ }^{*}$, Molla Md Islam ${ }^{2}$, Rahman Md Hamidur ${ }^{3}$ and Saqueeb Nazmus ${ }^{4}$ \\ ${ }^{1}$ Department of Pharmaceutical Technology, University of Dhaka, Dhaka-1000, Bangladesh. \\ ${ }^{2}$ Department of Pharmacy, Jagannath University, Dhaka-1100, Bangladesh. \\ ${ }^{3}$ Department of Pharmacy, World University of Bangladesh, Panthapath, Dhaka-1205, Bangladesh. \\ ${ }^{4}$ Department of Clinical Pharmacy and Pharmacology, University of Dhaka, Dhaka-1000, Bangladesh.
}

Publication history: Received on 10 December 2019; revised on 16 December 2019; accepted on 19 December 2019

Article DOI: https://doi.org/10.30574/gscbps.2019.9.3.0234

\begin{abstract}
Naproxen, a commonly used non-steroidal anti-inflammatory drug (NSAID), for pain management and immediate release tablet is more patient convenient for managing pain immediately. In this study, six different formulations (F1F6) of naproxen immediate release tablets were prepared by wet granulation method and were designed to increase disintegration and drug release property by using two super disintegrants named sodium starch glycolate and crospovidone in different concentrations. After preparing the formulations, the physicochemical properties were evaluated according to the United States Pharmacopoeia (USP) guideline. Among all the formulations, F6 proved to be the best immediate release formulation in terms of disintegration time (1.23 min) and dissolution ( $99.56 \%$ after 30 minutes). Other tablet properties of formulation F6 like average weight, diameter, thickness, hardness and friability were also within the USP limit. Drug release kinetics were analyzed through different models such as zero order, first order, Higuchi, Korsmeyer-Peppas and Hixson-Crowell model where the optimized formulation (F6) was best fitted in Hixson-Crowell model. The release mechanism of naproxen followed non-swellable matrix-diffusion, Quasi-Fickian diffusion. Moreover, F6 formulation was stable at $45^{\circ} \mathrm{C} / 75 \% \mathrm{RH}$ for a period of three months and compatibility study was conducted by using Fourier Transform Infrared Spectroscopy (FTIR) where no change was found in stability and peak positions. The optimized formulation (F6) was compared with eight (8) different naproxen immediate release tablet brands (B1-B8) available in market based on dissolution. F6 showed better release property than the marketed tablets. Thus, it can be comprehended that the formulation F6 was robust and stable with a better immediate release property.
\end{abstract}

Keywords: Naproxen; Comparative study; Immediate release tablet; Super disintegrants

\section{Introduction}

An immediate release dosage form allows a manufacturer to extend market exclusivity as well as offers patient convenient dosage form or dosage regimen. Immediate release tablets are designed in such a way that disintegrate fast and release the medications without any special rate controlling features. Presently immediate release tablets are gaining popularity and acceptance as a drug delivery system since they are easy to administer, have fast onset of action, are cost-effective and ensure better patient compliance [1].

Naproxen, a non-steroidal anti-inflammatory drug (NSAID), possesses analgesic and antipyretic properties. Its sodium derivative is an odorless crystalline powder that is absorbed quickly and entirely from the alimentary tract with $95 \%$ of in-vivo bioavailability and extensively metabolized to 6-o-desmethyl naproxen [2].

\footnotetext{
${ }^{*}$ Corresponding author

E-mail address: yasif@du.ac.bd
}

Copyright (C) 2019 Author(s) retain the copyright of this article. This article is published under the terms of the Creative Commons Attribution Liscense 4.0 
The basic tactic used in manufacturing immediate release tablets is the use of super disintegrants. The main objective of this research was to explore the effect of different super disintegrants on the release of naproxen sodium in different concentrations and comparison with the available marketed naproxen tablets to develop more superior immediate release tablet.

\section{Material and methods}

\subsection{Excipients and instruments}

Naproxen sodium was received as gift sample from Beximco Pharmaceuticals Ltd. Crospovidone, sodium starch glycolate, lactose, magnesium stearate and povidone K-30 were bought from Merck, Germany. Talc were purchased from Rupali Chemic. Ltd. Mumbai, India.

Electronic balance and moisture analyzer of Metlar Toledo, Japan, IMA Killian tablet compression machine of Romaco Pharmatechnik GmbH, Germany, Monsanto hardness tester, friability tester (single drum), USP disintegration test apparatus and USP dissolution apparatus I of Electrolab, India, double beam UV-spectrophotometer of Shimadzu, Japan, Fourier Transform Infrared Spectroscopy (FTIR) machine of Perkin Elmer, USA were used to conduct the study.

\subsection{Preparation of immediate release naproxen tablets}

Tablets containing $250 \mathrm{mg}$ of naproxen sodium were prepared by wet granulation process. Two batches of total six formulations were manufactured by using different concentration of crospovidone (F1, F2, F3) and sodium starch glycolate (F4, F5, F6). Firstly, drugs and excipients weighed as per the Table 1. Experimental drug, super disintegrants and diluents were passed through 16-mesh and mixed properly for a definite period. Then povidone K-30 was dissolved in purified water for preparing granulating solution and then mixed with the mixture. After that, passed the wet mass through an 8-mesh screen and dried until LOD was achieved between $1.5 \%$ and $2.5 \%$. Then magnesium stearate and talc were passed through 30-mesh, mixed and blended with the primary mixture. After that, the blended powder was directly compressed and the tablets were prepared [3].

Table 1 Formulation of naproxen sodium immediate release tablets (amounts were taken in milligram).

\begin{tabular}{lllllll}
\hline Ingredients & F1 & F2 & F3 & F4 & F5 & F6 \\
\hline Naproxen sodium & 250 & 250 & 250 & 250 & 250 & 250 \\
Lactose & 62.98 & 56.34 & 53.14 & 63 & 56.34 & 49.86 \\
Crospovidone & 6.56 & 13.2 & 16.4 & - & - & - \\
Sodium starch glycolate & - & - & - & 6.56 & 13.2 & 19.68 \\
Magnesium Stearate & 2.1 & 2.1 & 2.1 & 2.1 & 2.1 & 2.1 \\
Talc & 2.36 & 2.36 & 2.36 & 2.36 & 2.36 & 2.36 \\
Povidone K-30 & 4 & 4 & 4 & 4 & 4 & 4 \\
Total weight & 328 & 328 & 328 & 328 & 328 & 328 \\
\hline
\end{tabular}

\subsection{Evaluation of physical properties of tablets}

Individually 20 experimental tablets were taken to measure their diameter, thickness, hardness, average weight and friability according to the USP guideline.

\subsection{Determination of disintegration time}

USP disintegration device contains 3 inches long six glass tubes. The tubes are open at the upper side and held against a 10-mesh screen at the bottom end of the basket rack assembly. About $900 \mathrm{ml}$ of water was taken in both $1000 \mathrm{ml}$ beaker and then these beakers were positioned into the apparatus. One naproxen tablet was put in every single tube \& a plastic disk was positioned over each tablet \& then the basket rack was accurately placed into the beaker. A temperature at $37 \pm 0.5{ }^{\circ} \mathrm{C}$ was maintained. A motor driven machine through a space of 5-6 cm moved up and down the basket at 28-32 cycles per minute. The time required by the tablets to pass through the sieve was termed, as the disintegration time and the average time were calculated [4]. 


\subsection{In-vitro dissolution study}

This study for experimental naproxen tablets were conducted by using USP paddle technique in a solution of phosphate buffer $(900 \mathrm{ml}, \mathrm{pH} 6.8)$. The rotation speed of paddle was $50 \mathrm{rpm}$ and temperature were maintained at $37 \pm$ $0.5{ }^{\circ} \mathrm{C}$. At an interval of $5,10,15,30$ and 45 minutes, $5 \mathrm{ml}$ dissolution media was withdrawn from the dissolution device which was replaced with fresh media. Absorbance of the withdrawn solutions was measured by using UV spectrophotometer at $272 \mathrm{~nm}$ [5].

\subsection{Kinetic data analysis}

The studies of drug release kinetic were conducted by zero order, first order, Higuchi, Korsmeyer-Peppas and HixsonCrowell model [6].

\subsection{Stability study}

The experimental formulations were kept at $45{ }^{\circ} \mathrm{C} / 75 \% \mathrm{RH}$ for three months in a stability chamber according to the ICH guideline [7].

\subsection{Compatibility studies by FTIR}

The experimental formulations were undergone compatibility studies by using FTIR tactic. The scanning resolution was $1 \mathrm{~cm}^{-1}$ over the region of $4000-600 \mathrm{~cm}^{-1}[8]$.

\section{Results and discussion}

\subsection{Evaluation of pre-compression properties}

The flow properties of the experimental naproxen granules were determined as per the USP guideline which are presented in the Table 2.

Table 2 Granules characterization of naproxen sodium formulations.

\begin{tabular}{lllllll}
\hline $\begin{array}{l}\text { Pre-compression properties of } \\
\text { granules }\end{array}$ & F1 & F2 & F3 & F4 & F5 & F6 \\
\hline LOD & 1.66 & 1.80 & 1.74 & 1.68 & 2.17 & 1.71 \\
Bulk density $\left(\mathrm{gm} / \mathrm{cm}^{3}\right)$ & 0.56 & 0.59 & 0.47 & 0.45 & 0.53 & 0.47 \\
Tapped density $\left(\mathrm{gm} / \mathrm{cm}^{3}\right)$ & 0.65 & 0.63 & 0.55 & 0.53 & 0.61 & 0.51 \\
Hausner's ratio & 1.16 & 1.07 & 1.17 & 1.12 & 1.15 & 1.09 \\
Angle of repose & 31.5 & 27.8 & 33.16 & 30.28 & 34.35 & 25.88 \\
Granules Flow Property & Good & Excellent & Good & Excellent & Good & Excellent \\
\hline
\end{tabular}

\subsection{Physical properties}

Average weight, diameter, thickness, hardness and friability of the formulated tablets were measured according to the USP guideline and tabulated in Table 3. All the data were within the limit.

Table 3 Physical properties of the tablets.

\begin{tabular}{|c|c|c|c|c|c|c|}
\hline Formulation & $\begin{array}{l}\text { Average } \\
\text { (mg) }\end{array}$ & weight & $\begin{array}{l}\text { Diameter } \\
(\mathrm{mm})\end{array}$ & $\begin{array}{l}\text { Thickness } \\
\text { (mm) }\end{array}$ & $\begin{array}{l}\text { Hardness } \\
\left(\mathrm{Kg} / \mathrm{cm}^{2}\right)\end{array}$ & Friability (\%) \\
\hline F1 & $328 \pm 0.12$ & & $7.9 \pm 0.01$ & $4.26 \pm 0.01$ & $4 \pm 0.22$ & 0.135 \\
\hline $\mathrm{F} 2$ & $328 \pm 0.12$ & & $8.0 \pm 0.01$ & $4.26 \pm 0.01$ & $4.3 \pm 0.45$ & 0.147 \\
\hline F3 & $328 \pm 0.8$ & & $8.0 \pm 0.01$ & $4.25 \pm 0.01$ & $4.2 \pm 0.43$ & 0.142 \\
\hline $\mathrm{F} 4$ & $328 \pm 0.5$ & & $7.8 \pm 0.02$ & $4.24 \pm 0.01$ & $4.1 \pm 0.66$ & 0.183 \\
\hline F5 & $328 \pm 0.5$ & & $7.8 \pm 0.02$ & $4.24 \pm 0.01$ & $4.8 \pm 0.66$ & 0.172 \\
\hline F6 & $328 \pm 0.6$ & & $7.9 \pm 0.01$ & $4.24 \pm 0.01$ & $4.7 \pm 0.6$ & 0.175 \\
\hline
\end{tabular}




\subsection{Determination of disintegration time and dissolution study}

Disintegration time was determined for all the formulations (F1-F6). Formulation F6 showed the lowest disintegration time, 1.23 minutes whereas formulation F1 showed the highest disintegration time, 2.34 minutes. The findings are displayed in Table 4. In dissolution study, all formulation batches F1-F6 had presented an immediate release property between 96.25 and $99.56 \%$ after 30 minutes. Therefore, from the study it can be claimed that, crospovidon at 2, 4 and $5 \%$ concentration (range $2-5 \% \mathrm{w} / \mathrm{w}$ ) and sodium starch glycolate concentration at 2, 4 and $6 \%$ (range $2-8 \% \mathrm{w} / \mathrm{w}$ ) can be used to formulate naproxen sodium immediate release tablets. Comparing the release profile of all the formulations in Table 5, F6 showed the best results, $86.29 \%$ of drug release after 15 minutes and 99.56\% after 30 minutes. So, F6 was well formulated as immediate release tablet since it presented better disintegration (1.23 minutes) and drug release properties (99.56\% after 30 minutes) compared to the other formulations.

Table 4 Disintegration time of naproxen sodium immediate release tablets

\begin{tabular}{cc}
\hline Formulation & Disintegration Time (min) \\
\hline F1 & 2.34 \\
F2 & 2.12 \\
F3 & 1.29 \\
F4 & 1.78 \\
F5 & 1.56 \\
F6 & 1.23 \\
\hline
\end{tabular}

Table 5 Drug release profile of naproxen sodium immediate release tablets.

\begin{tabular}{llllll}
\hline Formulation & \multicolumn{5}{c}{ \% of drug release } \\
\cline { 2 - 6 } & $\mathbf{5} \mathbf{~} \mathbf{m i n}$ & $\mathbf{1 0} \mathbf{~}$ in & $\mathbf{1 5} \mathbf{~}$ in & $\mathbf{3 0} \mathbf{~}$ in & $\mathbf{4 5} \mathbf{~}$ in \\
\hline F1 & 27.25 & 40.56 & 85.26 & 96.25 & 101.30 \\
F2 & 29.56 & 45.25 & 82.53 & 98.36 & 102.50 \\
F3 & 32.18 & 48.35 & 83.56 & 98.25 & 101.94 \\
F4 & 30.14 & 47.56 & 85.48 & 97.58 & 101.36 \\
F5 & 35.25 & 48.24 & 85.96 & 99.24 & 102.88 \\
F6 & 36.58 & 49.58 & 86.29 & 99.56 & 103.73 \\
\hline
\end{tabular}

\subsection{Drug release kinetics analysis}

Kinetics findings of formulation F6 is graphically displayed in Figure 1. From the graph, it was understood that F6 formulation was best fitted to the Hixson-Crowell model where the regression coefficient $\left(R^{2}\right)$ was 0.991 . The release pattern of the experimental drug from the polymeric system was analyzed by using Korsemeyer-Peppas equation. For formulation F6, the " $\mathrm{n}$ " value was seen as 0.46 , which was less than 0.5 , demonstrating the drug release mechanism followed non-swellable matrix-diffusion, Quasi-Fickian diffusion [9]. 

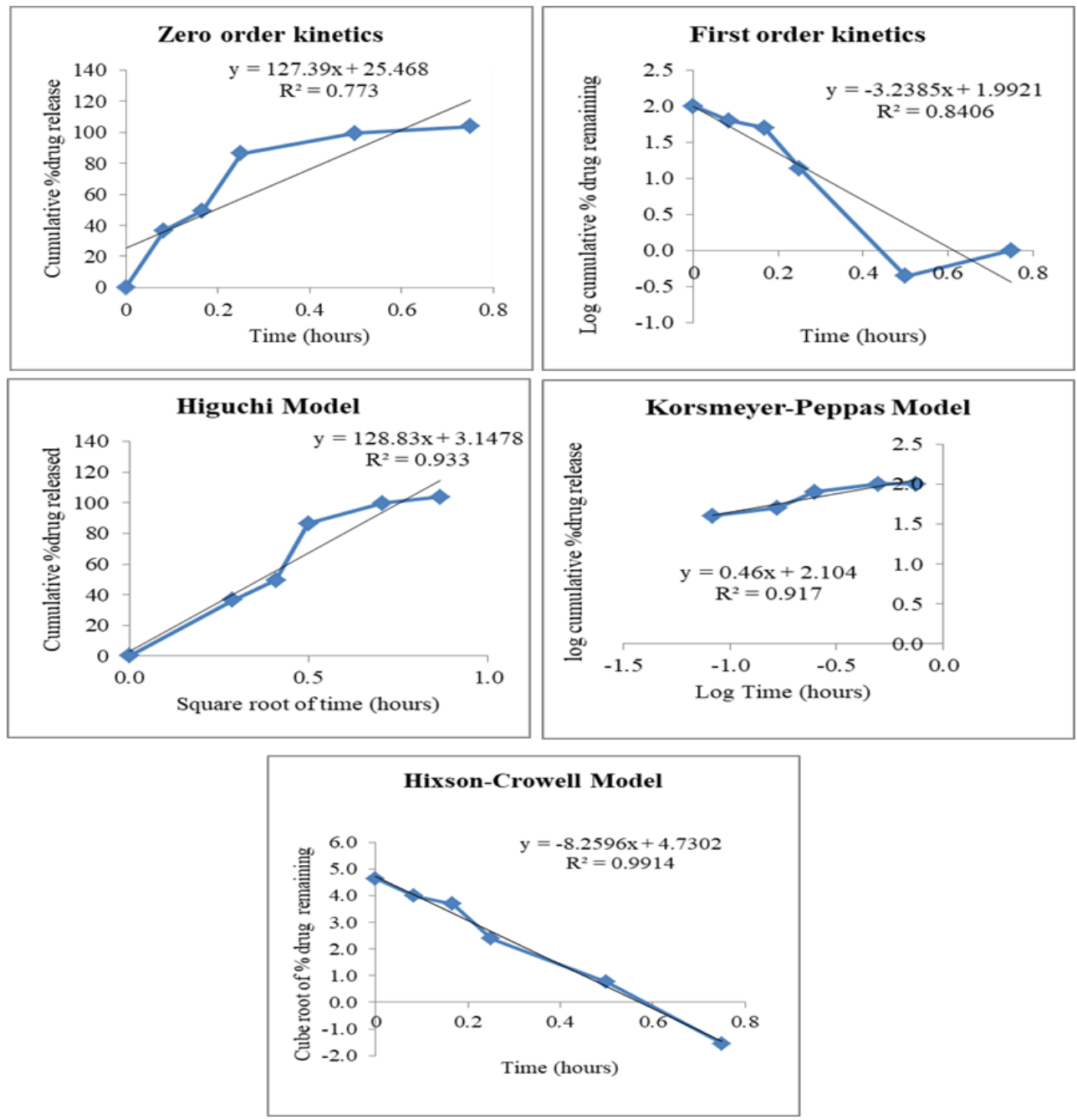

Figure 1 Drug release kinetics analysis of optimized formulation F6 by zero order, first order, Higuchi, KorsmeyerPeppas and Hixson-Crowell model.

\subsection{Stability study}

The optimized formulation F6 was undergone stability studies at $45{ }^{\circ} \mathrm{C} / 75 \% \mathrm{RH}$ for three months. After three months, naproxen sodium immediate release tablet did not show any alteration in physical properties.

\subsection{Compatibility study}

When the crushed powders of drug products were observed, there was no change in peaks. This finding indicated that no polymorphic changes occurred while manufacturing the tablets with the experimental excipients. FTIR results are showed in Figure 2. 
A.

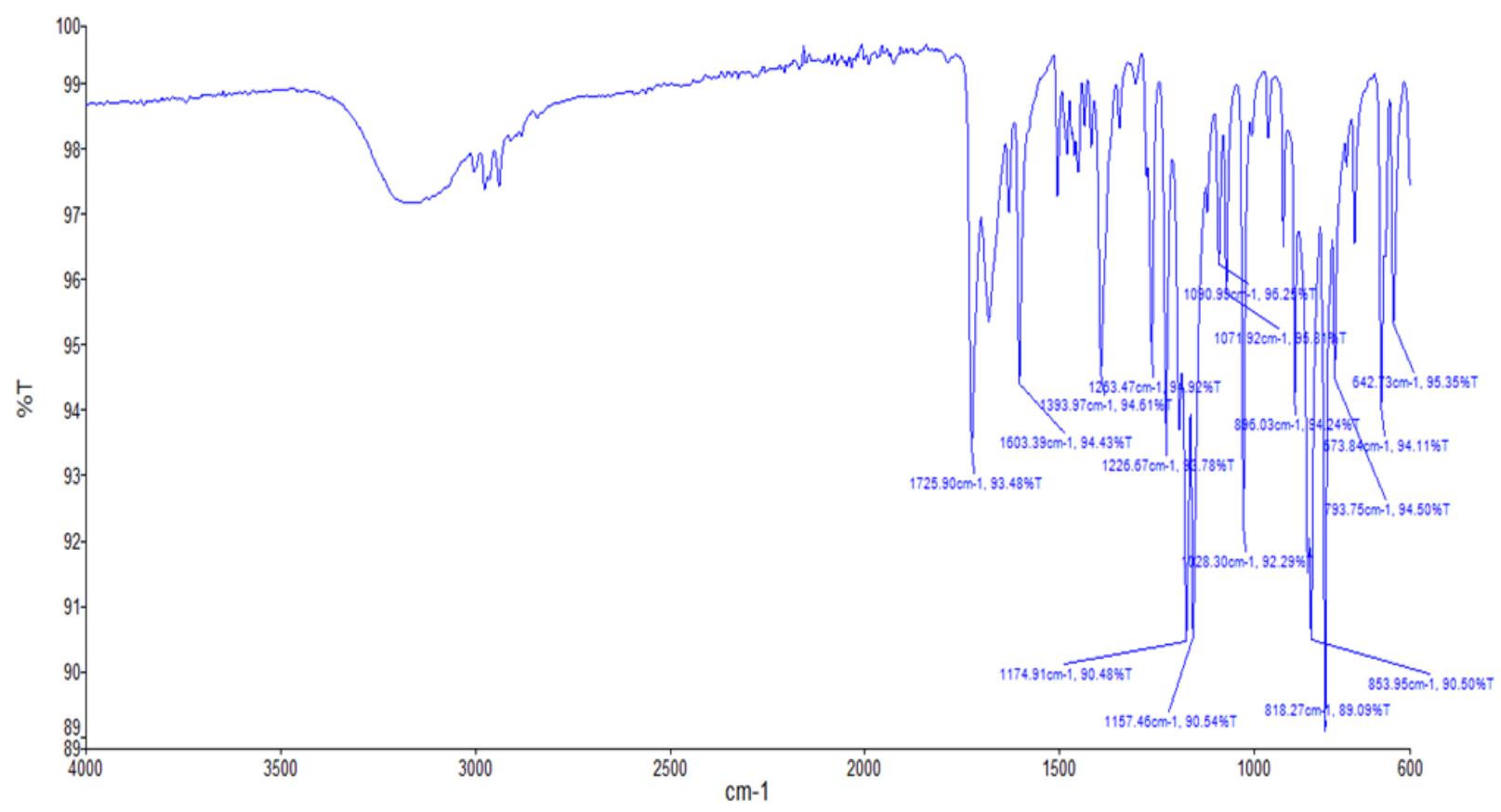

B.

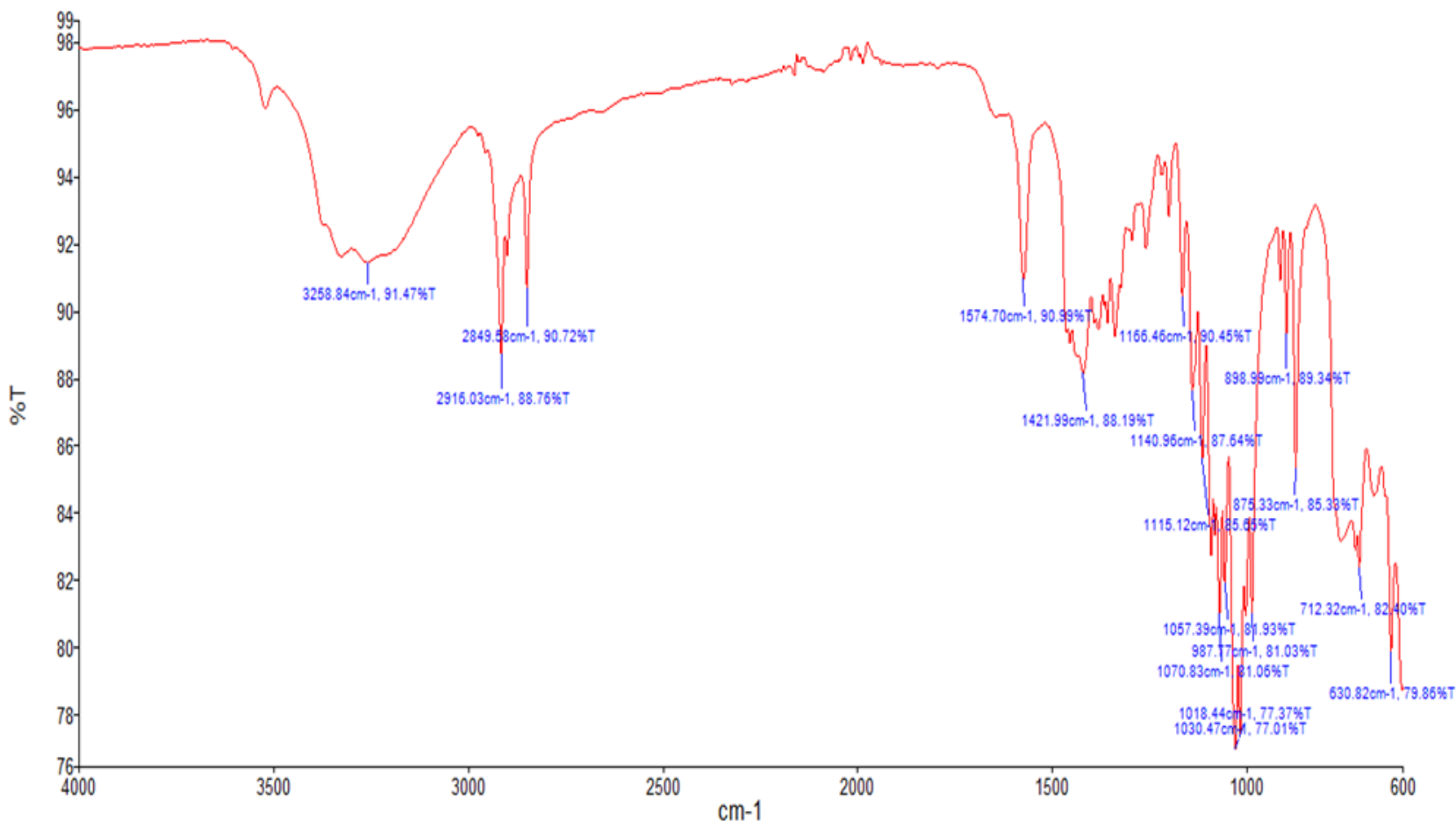


C.

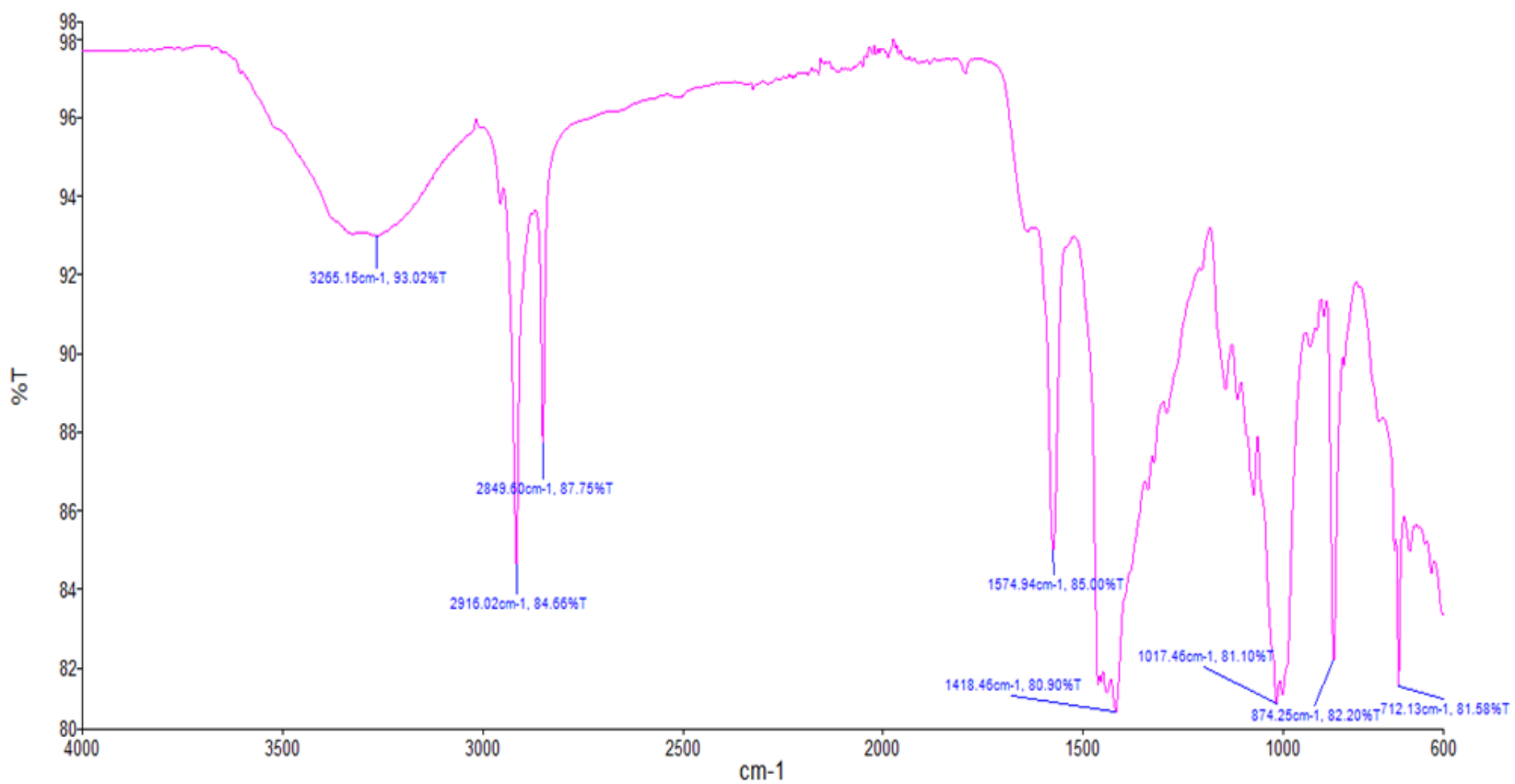

D.

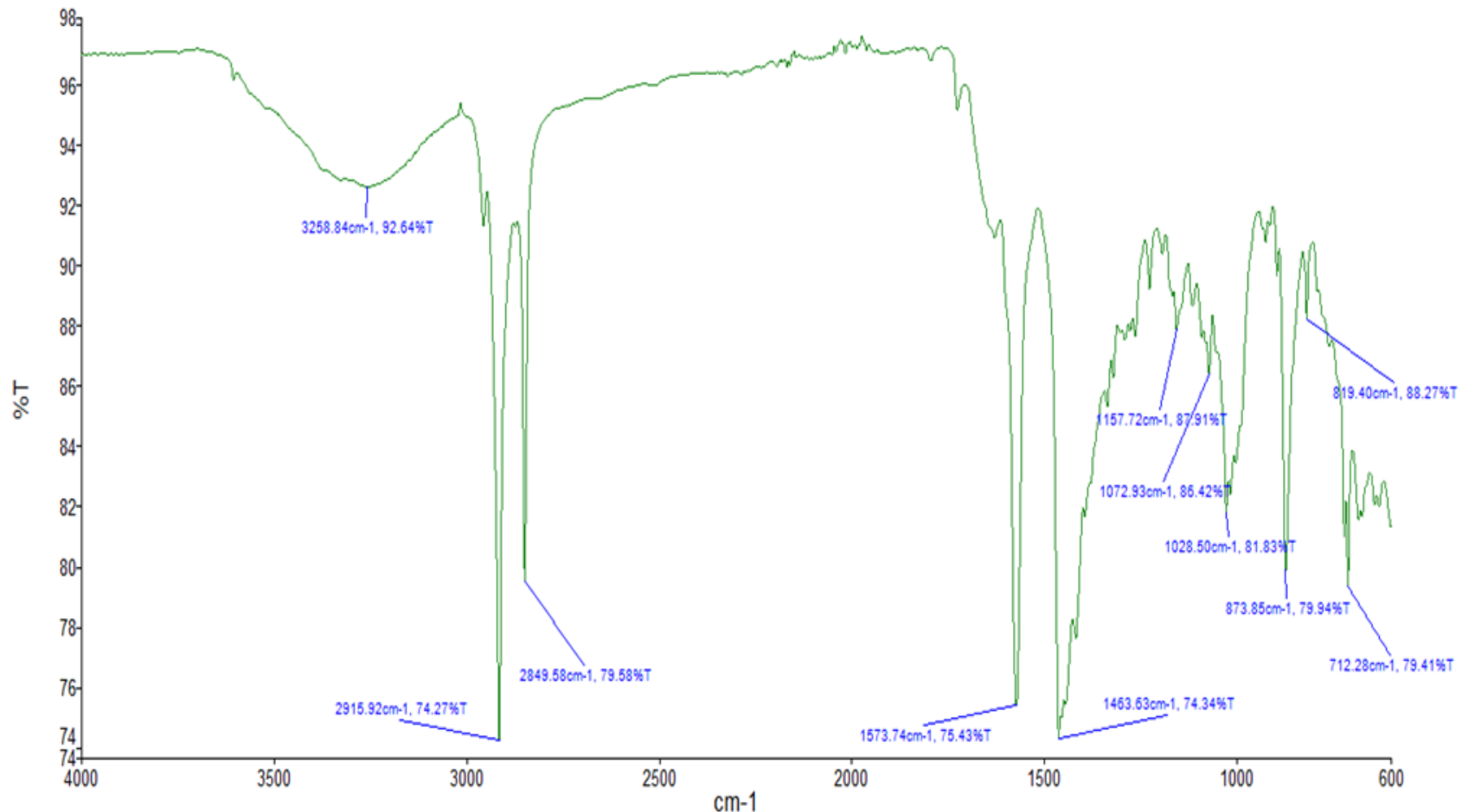


E.

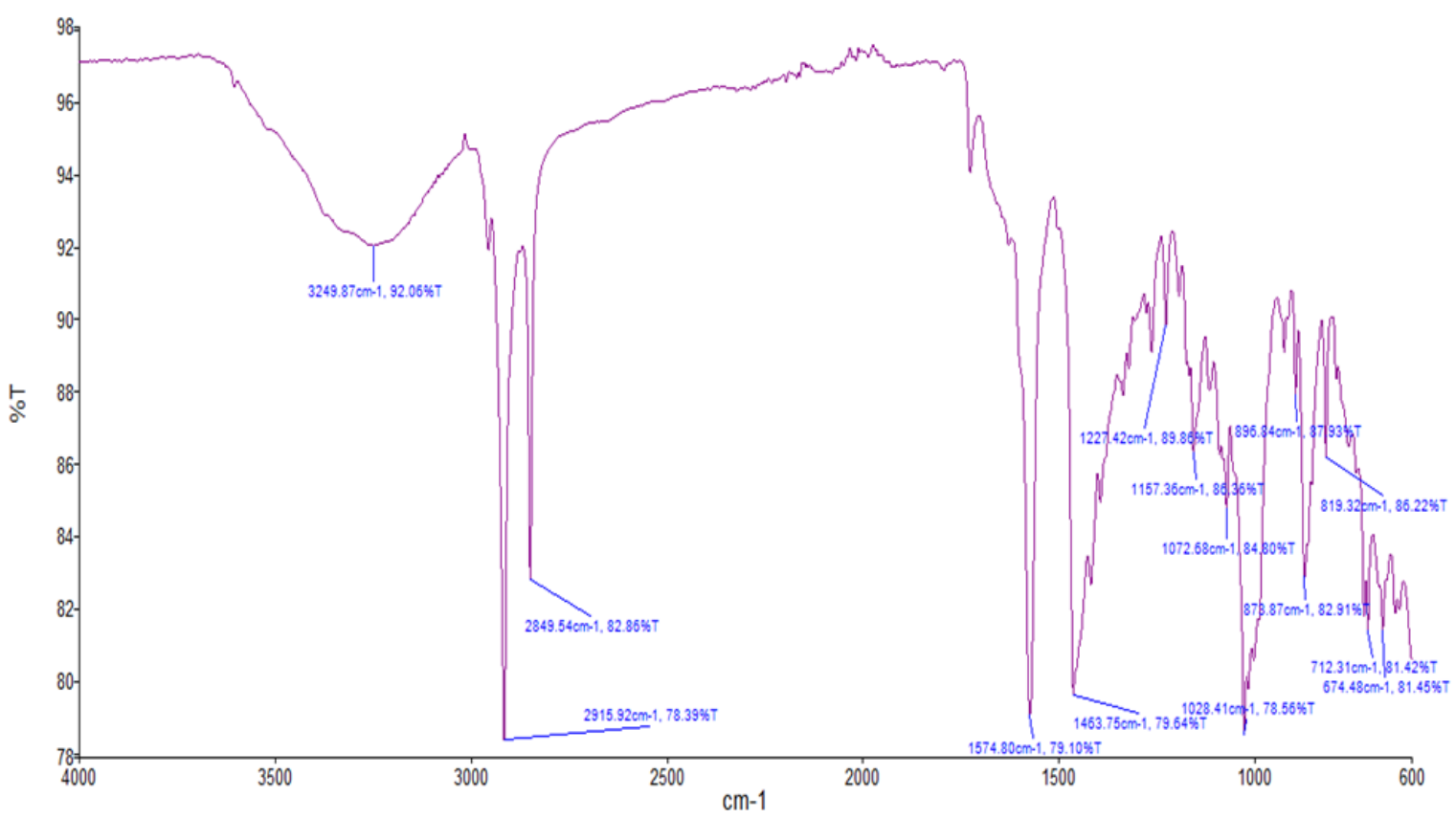

Figure 2 FTIR spectrum of (A) Naproxen pure drug, (B) Crospovidone with other excipients, (C) Sodium starch glycolate with other excipients, (D) Naproxen and Crospovidone with other excipients and (E) Naproxen and Sodium starch glycolate with other excipients.

\subsection{Comparison of the in-vitro drug release of the optimized formulation with the marketed brands}

Eight (8) different brands named B1 to B8 of naproxen sodium $250 \mathrm{mg}$ tablet were bought from the market and their drug release pattern was analyzed by dissolution study. Then the findings were compared with the dissolution profile of optimized formulation F6. The result is showed in Figure 3. From the figure, it can be easily observed that the optimized formulation was more superior to the marketed brands in term of dissolution.

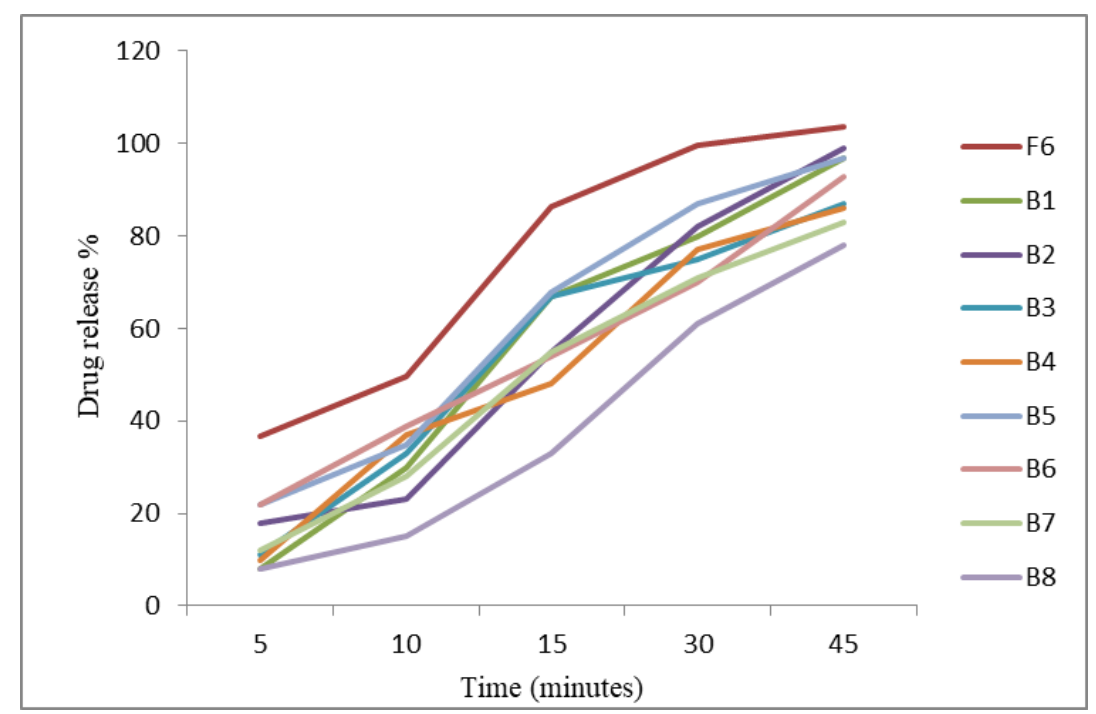

Figure 3 Comparison of the in-vitro drug release of the optimized formulation F6 with the marketed naproxen sodium tablet brands (B1-B8).

\section{Conclusion}

This study demonstrated a successful preparation and evaluation of naproxen sodium immediate release tablets by using two different super disintegrants in different concentrations. Formulation F6 was the optimized formulation 
containing $6 \% \mathrm{w} / \mathrm{w}$ sodium starch glycolate as super disintegrant. The optimized formulation was also compared with some marketed brands based on dissolution in which it also showed superiority over the marketed brands. Stability study and compatibility study were also done by stability chamber and FTIR. Therefore, it can be comprehended that the optimized formulation F6 was robust and stable with a better immediate release property.

\section{Compliance with ethical standards}

\section{Acknowledgments}

The authors acknowledge the help of Biomedical Research Centre, University of Dhaka for using their laboratories and Beximco Pharmaceuticals Ltd. for providing the gift sample of active ingredient.

\section{Disclosure of conflict of interest}

The authors declare no conflict of interest.

\section{References}

[1] Lachman L, Herbert AL and Joseph LK. (1990). The theory and practice of industrial pharmacy. Varghese Publishing House, Bombay, 171-196.

[2] Laurence LB, John SL and Keith LP. (2005). Naproxen, the pharmacological basis of therapeutics. Goodman and Gilman, McGraw-Hill, New Delhi, 700.

[3] Di Martino P, Malaj L, Censi R and Martelli S. (2008). Physico-chemical and technological properties of sodium naproxen granules prepared in a high-shear mixer-granulator. Journal of Pharmaceutical Sciences,97(12), 5263-5273.

[4] Wagh MP, Yewale CP, Zate SU, Kothawade PI and Mahale GH. (2010). Formulation and evaluation of fast dispersible tablets of aceclofenac using different superdisintegrant. International Journal of Pharmacy and Pharmaceutical Sciences,2(1), 154-157.

[5] Manivannan R, Parthiban KG, Shaik S, Senthilkumar B and Senthilkumar N. (2010). Formulation development and evaluation of naproxen sodium tablets USP. International Journal of Drug Development and Research, 2(1), 47-53.

[6] Ryakala H, Dineshmohan S, Ramesh A and Gupta VRM. (2015). Formulation and in vitro evaluation of bilayer tablets of nebivolol hydrochloride and nateglinide for the treatment of diabetes and hypertension. Journal of Drug Delivery, 1-14.

[7] Shah DP, Jain VC, Sonani NG, Dalvadi HP and Patel NJ. (2010). Influence of various excipients on quality control parameter of aceclofenac tablets containing SSG. International Journal of Pharmaceutical Sciences, 16(1), 113121.

[8] Sikdar KYK, Ahamed A, Alam MM, Sarkar MR and Sajeeb BK. (2019). Formulation and in-vitro evaluation of bilayer tablets of atenolol and amlodipine. Bangladesh Pharmaceutical Journal, 22(2), 153-169.

[9] Paarakh MP, Jose PA Setty CM and Christoper GVP. (2018). Release kinetics-concepts and applications. International Journal of Pharmacy Research \& Technology, 8(1), 12-20.

\section{How to cite this article}

Sikdar KMK, Molla MI, Rahman MH and Saqueeb N. (2019). A comparative study on Naproxen Sodium tablets formulating with different super disintegrants. GSC Biological and Pharmaceutical Sciences, 9(3), 76-84. 